\title{
A GESTÃO DA VIOLÊNCIA ESCOLAR
}

\author{
The management of school violence
}

\author{
Maria Isabel da Silva Leme
}

D outora em PsicologiaE scolar e do D esenvolvimento Humano, Professora do Instituto de PsicologiadaUniversidadedeSão Paulo (USP),São Paulo, SP - Brasil, e-mail:belleme@ usp.br

\section{Resumo}

0 trabalho analisa o desafio enfrentado atualmente pelos educadores brasileiros, a saber, o crescimento da violência escolar, constatado em várias pesquisas. Neste sentido, a evolução da violência escolar é focalizada em primeiro lugar, desde os primeiros registros de seu crescimento, que despertou a atenção dos pesquisadores, logo após a redemocratização brasileira, até dados mais recentes dos anos 2000. Em segundo lugar, o fenômeno é caracterizado em termos das suas formas de manifestação mais frequentes, que também têm variado ao longo da sua evolução, passando da depredação do patrimônio, inicialmente a transgressão mais frequente, para violências contra a pessoa. São também abordadas as variáveis já identificadas pelas pesquisas como associadas à manifestação da violência escolar, como, por exemplo, porte da cidade, tamanho do estabelecimento, desigualdade social, etc. Esta panorâmica permite observar, além do crescimento constante nos índices de violência escolar, a sua disseminação, e também, o agravamento do problema, em virtude das formas de manifestação terem se tornado cada vez mais explícitas e pessoais. Ante essa situação, é discutida a gestão da violência escolar, desde as políticas públicas já

Rev. Diálogo Educ., Curitiba, v. 9, n. 28, p. 541-555, set./ dez. 2009 
implementadas pelas administrações centrais até o que pode ser feito no âmbito da escola. Nesta perspectiva, discute-se as novas demandas que a violência na escola traz, não só para o diretor escolar, mas para todos os integrantes da comunidade.

Palavras-chave: Violência. Escola. G estão escolar. Políticas públicas.

\begin{abstract}
The study aims to discuss the management of school violence, whose growth has been observed in many studies. It is focused in this analysis the evolution of school violence, from the first records of its' growth, until the most recent data. Then, the phenomenon is characterized in terms of its' most frequent forms of expression, which also have varied throughout its evolution, going from depredation, initially the most common transgression, to violence against the person. It is also discussed the variables already identified by research as associated with the onset of school violence, such as size of the city, size of school and social inequality etc. This overview shows that in addition to the constant growth and spread in rates of school violence, the forms of expression have become increasingly explicit and personal. In front of this situation, we discuss the management of school violence, at a more general level, provided by public policies already implemented by the central government and some of the results already achieved, until more specifically at the scope of the school. In the same vein, the new challenges that violence brings to school are considered, which may not respond merely to restrictive measures, but that should mobilize all members of the community, in actions collectively decided and implemented.
\end{abstract}

Keywords: Violence. School. School management. Public policies.

\title{
INTRODUÇÃO
}

O objetivo deste artigo é discutir os desafios colocados para a formação e atuação docente ante a violência escolar, focalizando, em primeiro lugar, este fenômeno segundo alguns resultados de pesquisa. A

Rev. Diálogo Educ., Curitiba, v. 9, n. 28, p. 541-555, set./ dez. 2009 
preocupação com a violência escolar tem suscitado cada vez mais investigações, não só em função do paradoxo que ela representa em relação à missão educativa da escola, mas pelas consequências em longo prazo que dela podem decorrer. Essas pesquisas vão permitir definir os tipos de incidentes mais frequentes sofridos pelos alunos, sua incidência, prováveis causas, e as intervenções que têm sido realizadas, desde o nível macro, das políticas públicas até o escolar, sendo que nos deteremos um pouco mais no papel do diretor na gestão da violência na escola, bem como suas implicações para a atuação e formação docente.

\section{As pesquisas sobre violência escolar}

Segundo Gonçalves e Sposito (2002), a preocupação com a questão da violência escolar ganhou espaço na pesquisa apenas depois do processo de democratização brasileira na década de 1980, o que ocorreu concomitante à disseminação da criminalidade e delinquência. Essas pesquisas eram em sua maioria do tipo survey, levantando entre os jovens das capitais brasileiras possíveis relações entre suas condições de vida com outros aspectos sociais como violência.

Uma revisão da produção de pesquisa brasileira sobre violência escolar (SPO SITO , 2001) identificou além da relativa recentidade dos estudos apontada acima, outras dificuldades, como a aferição da real magnitude do fenômeno, em função das iniciativas ainda pouco organizadas do poder público na coleta de informações, faltando consistência no monitoramento e registro das ocorrências. Apesar dessas falhas na coleta de informações, constata-se ao longo da década de 1980 um crescimento relativamente constante na violência escolar, destacando-se as seguintes transgressões: depredação de patrimônio, furtos, roubos, agressões físicas e verbais entre alunos, assim como agressões destes últimos contra professores. A ocorrência do fenômeno nessa época estava relacionada ao tamanho do estabelecimento escolar e ao porte da cidade, como capitais dos estados. A partir dos anos 1990, observam-se algumas mudanças, como o aumento da violência interpessoal entre estudantes, expressas, principalmente, em agressões verbais e ameaças, persistindo a depredação de patrimônio como uma transgressão frequente. O utra mudança constatada foi a disseminação do fenômeno para cidades de médio porte, sendo ineficazes as medidas de segurança tomadas, como por exemplo, a instalação de câmaras e outros dispositivos.

Rev. Diálogo Educ., Curitiba, v. 9, n. 28, p. 541-555, set./ dez. 2009 
Já nessa época, o aumento da violência constatado nas pesquisas era atribuído à crescente exclusão social, e consequente aumento da criminalidade, em virtude da frustração das aspirações de ascensão social e consumo das classes menos privilegiadas. Uma pesquisa realizada nessa época em escolas públicas de São Paulo revelou que as agressões mais frequentessofridaspelosalunos eram furto (48\%), ameaças (36\%), danificação de pertences (33\%) e agressão física (4\%). A prática de atos violentos foi auto assumida por 25\% dos estudantes, manifestadas em depredações de patrimônio (25\%), e porte de arma (9\% arma branca e $2 \%$ de fogo).

Embora seja pertinente relacionar 0 aumento da violência escolar com a desigualdade social, e a consequente frustração de expectativas de ascensão e consumo, só esses fatores não são suficientes para explicar o fenômeno, pois observa-se a ocorrência de violência também em instituições privadas de ensino (ABRAMOVAY, 2004), onde o nível de afluência econômica é geralmente mais alto.

Um estudo comparativo entre os dois tipos de instituição de ensino, uma pública e outra privada(CAMACHO , 2001) demonstra porque a desigualdade social éinsuficiente como explicação para aviolência escolar. Isto porque, como mencionado acima, na escola privada a violência também está presente, tendendo apenas a manifestar-se de modo diferente, mais disfarçada em brincadeiras e apelidos, enquanto na escola pública ela é mais explícita. Foram encontradas ainda outras diferenças como: 1) locais onde se dão as ocorrências, o pátio mais frequente na pública ea sala de aula na privada; 2) os perpetradores de atos violentos na escola pública são em geral indivíduoscujaaparência se diferenciafrequentementepelacorpulência, enquanto na escola privada ocorre o oposto, os agressores são os estudantes admirados justamente por encarnarem o ideal estético (relação peso/ altura) e econômico veiculado pela mídia; 3) a intolerância contra a diferença, em geral a motivação principal para as agressões, também manifestada de modo específico, na escola pública contra negros, orientais e homossexuais, enquanto na privada, contra aqueles que fogem ao padrão estético de relação altura/ peso e de consumo difundido.

Constata-seque o tipo deagressão apontada como amais frequente pelos alunos varia entre as pesquisas, o que talvez possa ser atribuído ao tipo de instrumento usado ou amostra estudada. D ados coletados em 5 capitais brasileiras e no Distrito Federal (ABRAMOVAY, 2004) mostraram que: $83,4 \%$ dos estudantes consideram que a violência ocorre em sua escola, sendo o roubo de pertences a forma mais frequente, sofrido por $69 \%$ da amostra, metade dos quais foi vítima mais de uma vez no ano precedente à pesquisa. Além disso, 4,8\% informaram terem roubado pertences de

Rev. Diálogo Educ., Curitiba, v. 9, n. 28, p. 541-555, set./ dez. 2009 
colegas, e 4,7\% terem apanhado na escola. O utra informação importante prestada pelos alunos foi sobre a necessidade de regras claras, tanto de funcionamento como de disciplina. Apesar destas queixas, 49,2\% consideravam sua escola boa ou ótima e 43\% apenas regular.

Já em uma região considerada de alta exclusão social na periferia da cidade de São Paulo, a agressão física foi a forma de violência mais apontada pelos estudantes (47\%), sendo que metade relatou tê-la sofrido dentro da escola. Colegas foram apontados como perpetradores de 56\% dessas ocorrências, professores de 23\%, e funcionários de 14\%. 0 roubo, diferentementedo encontrado em outras pesquisas, foi asegunda ocorrência mais frequente, sendo relatado por $41 \%$ dos alunos, dos quais $21 \% 0$ sofreram mais de uma vez, e 21\% uma única vez (D OMING O S, 2005).

Por outro lado, em uma pesquisa realizada com uma amostra representativa de estudantes de Ensino Fundamental e Médio e seus diretores, deescolas públicas eprivadaspaulistas, osproblemas deconvivência para a grande maioria referiam-se a agressões verbais, como insultos e apelidos, ou veladas, como difamação, roubo, ou danificação de pertences. Agressões físicas foram apontadas mais raramente. Vale mencionar que, também segundo estes alunos, a existência de regras claras de disciplina eliminariamuitos problemas na escola(LEME, 2006). D e todo modo, o que se verifica a partir das pesquisas realizadas nos últimos 20 anos, é que boa parte alunos relata ter sofrido agressões dentro da escola, e embora essas variem quanto à frequência, elas se manifestam nas mesmas modalidades, como roubos ou danificação de pertences e as agressões verbais e físicas.

Como assinalado acima, as causas apontadas para o fenômeno, inicialmente atribuídas à exclusão social e suas decorrências, ainda não estão totalmente esclarecidas. Porém, uma hipótese bastante plausível é fornecida pelas pesquisas sobre uma forma específica de violência, a intimidação, ou bullying que vem sendo cada vez mais estudada no mundo todo, em função do seu aumento nas escolas, inclusive brasileiras. Além disso, por ser perpetrada de modo velado, na forma de ridicularização, piadas ou apelidos (ABRAMOVAY, 2004), sem motivação aparente, dificulta sua identificação não só pelos educadores, mas até pela vítima. Alguns autores atribuem este fenômeno a um problema mais amplo, a crise de valores ou socialização (CAMACHO , 2001). Um breve exame das definições de bullyingusadas nas pesquisas mostra que esta hipótese acerca da crise de valores é bastante provável: "É um conjunto de atitudes agressivas, intencionais erepetitivas, que ocorrem sem motivação evidente, adotadas por um ou mais alunos, causando dor, angústia e sofrimento a indivíduos mais fracos e incapazes de se defender" (FANTE, 2003, p. 58).

Rev. Diálogo Educ., Curitiba, v. 9, n. 28, p. 541-555, set./ dez. 2009 
E m suma, o bullyingcaracteriza-se como comportamento físico ou verbal, que pode assumir formas tanto explícitas como ataque físico, como veladas, como piadas, apelidos etc., que tem o potencial de causar dano físico e/ ou psicológico em suas vítimas (DE SO UZA; RIBEIRO, 2005), sendo o elemento da repetição considerado essencial para caracterizar o fenômeno.

Em termos quantitativos, o bullyingno Brasil parece ocorrer em proporção semelhante à de outros países, pois $63 \%$ dos alunos de Ensino Médio brasileiros relataram terem sofrido um episódio pelo menos no ano anterior à pesquisa, 25\% dos quais poderiam ser caracterizados como bullying pelo caráter repetitivo da sua ocorrência (FANTE, 2003). Um estudo comparativo da incidência do fenômeno em 28 países, revelou que esta forma de agressão pode atingir entre 6 a $40 \%$ dos estudantes (D ICE et al., 2005). Um dado que vale ser lembrado pela sua gravidade é que dentre $67 \%$ das vítimas norte americanas de bullyingno Ensino Fundamental, cerca de 9\% relataram terem continuado a sofrer maus tratos no Ensino Médio, apresentando, inclusive, sintomas físicos como consequência do estresse sofrido (NEWMAN; HOLDEN; DELVILLE, 2005).

Com relação às características pessoais de vítimas e vitimizadores, as pesquisas revelam que podem ser encontradas semelhanças entre o que já foi verificado no Brasil (FANTE, 2003) e em outros países (ESLIA et al, 2004; TO BLIN et al., 2005; VIENSTRA et al., 2005), o que reforça a hipótese de uma crise de valores ou de socialização como uma das causas da violência escolar. Isto porque uma das principais semelhanças entre vitimizadores, identificadas nas pesquisas e mencionadas acima, é a motivação para a intimidação ou perseguição. Esta consiste na busca pelo agressor de admiração por parte dos colegas, pois deseja ver reconhecida sua coragem em transgredir. Outra semelhança constatada nas pesquisas reside na intolerância destes agressores ante 0 diferente, seja física ou psicologicamente.

As características da vítima, tanto as que se intimidam com a perseguição e não reagem, como as que reagem agressivamente também são semelhantes: isolamento social e características físicas ou psicológicas diferentes da média, tais como peso, voz, retraimento, ansiedade, hesitação em se defender etc. Além dessas diferenças, as vítimas costumam apresentar sintomas físicos do stress provocado pela intimidação como dor de cabeça, estômago, tonturas, lesões corporais frequentes, e psicológicas, como mudanças repentinas de humor, baixo rendimento escolar, resistência em frequentar a escola, medo de falar em público, e perda ou danificação de objetos pessoais.

Rev. Diálogo Educ., Curitiba, v. 9, n. 28, p. 541-555, set./ dez. 2009 
O convívio escolar também sofre consequências: o bullyingcria um clima de medo e perplexidade entre as vítimas, bem como para os demais membros da comunidade educativa que o testemunham sem saber o que fazer (FANTE, 2003). A violência na forma de tumulto, gritos, insultos, por suavez, dificultaa atividade pedagógica de muitos professores, em função da indisciplina reinante em sala de aula (CAMACHO, 2001; D O MING O S, 2005). Assim, seria de se esperar que os próprios alunos apresentem sugestões para garantir a ordem e o convívio na escola, algumas de cunho até repressivo, e que coincidem com o encontrado em outras pesquisas sobre a necessidade de estabelecimento de regras claras (ABRAMOVAY , 2004; LEME , 2006). São sugeridas medidas repressoras como presença de câmaras e aparato policial nas cercanias da escola, como também promoção de atividades que favoreçam o convívio escolar. Como se verá a seguir, algumas destas sugestões já foram implementadas por meio de iniciativas dos órgãos gestores, com resultados variados.

\section{A gestão da violência pelos óngãos públicos}

Em virtude das pesquisas sobre violência escolar serem ainda relativamente recentes, conforme apontado acima, os órgãos públicos dispõem de poucos dados para subsidiar suas políticas. Entretanto, algumas iniciativas valem serem relatadas, começando no âmbito federal pelo Ministério da Justiça, que criou uma comissão de especialistas para gerar diretrizes para combater a violência escolar. Tal iniciativa resultou no Programa Paz nas Escolas, implantado em 14 estados brasileiros (G O NÇALVES; SPO SITO , 2002). O programa consistiu basicamente em capacitação deeducadores em temas como direitos humanos, ética, cidadania e mediação de conflitos. Além disso, foram feitas campanhas para desarmamento da população, parcerias com organizações não governamentais para capacitações de outros profissionais como policiais, e estímulo às agremiações de jovens para a discussão da violência nas escolas.

No plano estadual e municipal, algumas iniciativas, como em São Paulo, datam do final da década de 1980, como o estímulo à democratização da gestão das escolas e abertura das mesmas nos finais de semana, que tiveram um impacto desigual na redução da violência nas unidades escolares. Na cidade de São Paulo, o programa "Pela vida, não à violência", na gestão de Luiza Erundina, consistiu em iniciativas variadas, desde a formação de funcionários como vigias, até a interação dos alunos com grupos de rapperspara discutir questões como racismo e preconceito nas escolas (GO NÇALVES; SPO SITO , 2002).

Rev. Diálogo Educ., Curitiba, v. 9, n. 28, p. 541-555, set./ dez. 2009 
Na década de 1990, também em São Paulo, valem ser mencionados dois programas, Comunidade Presente e Parceiros do Futuro. 0 primeiro visava criar uma cultura de valorização da paz pelo fortalecimento da cidadania, e o segundo promover solidariedade, respeito à pluralidade e um convívio mais ético (LIBERAL et al., 2005). Em Porto Alegre, uma parceria entre a Secretaria de E ducação e a Universidade Federal do Rio G rande do Sul em 1996, resultou, em primeiro lugar, em uma pesquisa que visava a realizar um diagnóstico dos problemas de convivência nas escolas. Esta pesquisa revelou que a violência contra a pessoa, como conflitos, ameaças, agressões físicas, representava 59\% dos incidentes nos estabelecimentos escolares. Esta iniciativa levou à realização do programa chamado "Ação Contra a Violência nas Escolas", orientado por princípios como diálogo, negociação no conflito, busca de entendimento do significado das incivilidades perpetradas pelosjovens (G O NÇALVE S; SPO SITO , 2002).

Em Minas Gerais, um estado onde também os índices de violência escolar eram altos, foram tomadas algumas iniciativas diferentes das relatadas acima, pois partiram da Polícia Militar, como o monitoramento das ocorrências, e um programa de proteção às escolas, denominado "Anjos da Escola", que estimulava a participação de todos os integrantes da comunidade escolarnessa tarefa. No âmbito da Secretaria de Municipal de Educação de Belo Horizonte foi realizado o programa "Rede de Trocas", que visava o intercâmbio de experiências bem sucedidas. Pela secretaria estadual, em parceria com a Universidade Federal de Minas G erais, foi realizado o programa "A genda da Paz" em 1999, voltado para a formação e capacitação de docentes (G O NÇALVE S; SPO SITO , 2002). A partir de 2003, na gestão de Aécio Neves, foi implantado o "Escola Viva, Comunidade A tiva" em escolas que tinham sido identificadas como mais necessitadas desse tipo de intervenção em avaliações de desempenho discente, que diminui na mesma proporção em que a violência está presente na escola. As ações consistiram em: abertura das escolas nos finais de semana; capacitação docente; reestruturação dos currículos, mais voltados para 0 atendimento de aspirações da comunidade; intensificação do processo de escolarização pelo acréscimo de um ano ao Ensino Fundamental, jornada de perío do integral, eatendimento psicopedagógico aos alunos. Verificou-se diferença significativa nos índices de violência registrados após a intervenção (CORREA, 2007).

Um aspecto quedificultaa consolidação dasintervenções contidas nesses programas é a desarticulação entre as várias instâncias envolvidas na implantação das políticas, e, também, seu caráter assistencialista

Rev. Diálogo Educ., Curitiba, v. 9, n. 28, p. 541-555, set./ dez. 2009 
(ABRAMOVAY et al., 2002). Outros fatores que interferem na consolidação dos programas são: descontinuidade, ocasionada pelas mudanças de gestão nas administrações estaduais e municipais; distorções na sua implementação, causadas pela burocracia, despreparo dos recursos humanos que atuam como multiplicadores nas formações, e a ausência de monitoramento confiável, que permita aferir a eficácia das medidas tomadas (G O NÇALVE S; SPO SITO , 2002). A lém disso, valelembrar que algumas iniciativas, como a abertura da escola nos finais de semana, só produzem resultados positivos em ambientes já mobilizados para a mudança, no sentido de uma gestão mais democrática. Este é um aspecto de grande importância, no qual nos deteremos a seguir, tratando especificamente do papel do diretor escolar na gestão da violência na escola e sua mobilização para a mudança.

\section{A gestão da violência na escola: o papel do diretor}

A construção de uma cultura escolar onde o respeito ao outro é enfatizado e a violência é desnecessária para expressar insatisfações depende de muitos fatores, entre eles, políticas públicas como as examinadas acima. Entretanto, como já colocado acima, tais iniciativas só têm um impacto positivo em ambientes mobilizados para a mudança, o que possibilita acolhê-las efetivamente. É justamente na construção desse ambiente propício que é extremamente importante o papel do diretor escolar.Isso porque é ele quem responde, não só pelo bom funcionamento institucional, mas ainda pelo cumprimento da função educativa da escola (SAVIANI, 2000). Tal papel consiste na tomada de decisões sobre a organização e coordenação de trabalhos, articulando e integrando os vários setores. Pesquisas têm constatado que o estilo de gestão, expresso nessas funções deliberativa e de coordenação estão associadas à melhoria do desempenho discente e profissionalismo docente. 0 estilo de gestão que prioriza o uso dos recursos e tempo para a aprendizagem, e o estabelecimento de um clima de confiança com regras claras e compartilhadas sobre os direitos e responsabilidades de cada um tem sido associado ao melhor desempenho discente (NAMO DE MELLO; ATHIÉ, 2003).

Porém, o compromisso do diretor com a aprendizagem dos alunos, expresso no seu estilo de gestão, tem outras implicações no que tange o objeto deste trabalho, ou seja, a violência escolar. Quando não há esse compromisso, é bem provável que o ambiente escolar seja permissivo

Rev. Diálogo Educ., Curitiba, v. 9, n. 28, p. 541-555, set./ dez. 2009 
em relação a professores que se ausentam com frequência em licenças médicas, ou atrasam-se etc, gerando revolta entre alunos, que veem violado seu direito ao ensino, o que pode representar um estopim para conflitos entre eles e o corpo docente. Segundo depoimento prestado por uma professora de escola pública (ALVES, 2006), o exercício do direito de tirar licenças e outras prerrogativas do corpo docente, além de ferir 0 do aluno ao ensino, tira a legitimidade dos professores que são assíduos e pontuais, que cobram o mesmo compromisso do aluno no cumprimento de tarefas, e na manutenção de um ambiente organizado em sala de aula, que viabilize a aprendizagem. Vale mencionar que os próprios alunos são favoráveis ao exercício da autoridade pelo professor, como foi verificado na pesquisa realizada entre alunos e diretores sobre a convivência na escola, já mencionada acima (LEME, 2006). Ao opinarem sobre as dificuldades percebidas na relação entre professores e alunos, apontadas por quase metade da amostra discente (40\%), cerca de um quinto atribuiu maiorimportânciaà existência de regras claras e rigorosas para a prevenção de indisciplina em sala de aula. Além disso, quase metade desta amostra (40\%) avaliou que a prevenção destes problemas está mais associada à forma pela qual o professor exerce sua autoridade em sala de aula, que, no seu entender, deve ser explícita. Entretanto, como já examinado, para ter legitimidade para exercer sua autoridade em sala de aula, é preciso que 0 professor cumpra o seu dever de ensinar ao aluno o conteúdo esperado para aquele perío do letivo e, também, que tenha sua autoridade em sala de aula garantida pela equipe gestora da escola. É necessário que os gestores garantam a contrapartida dos alunos, em termos do cumprimento das regras de disciplina que devem ser claras, assim como as sanções previstas para as transgressões às mesmas, aplicadas de modo justo e consistente. Esteéum aspecto que deve ser mais explorado em vistada suaimportância.

A disciplina fica mais explicitada se houver a efetiva participação de todos na elaboração das normas de conduta, o que aumenta ainda a probabilidade de que sejam seguidas, pelo sentido de responsabilidade pelas mesmas que é conferido aos participantes. Caso contrário, a observância das regras será, provavelmente, muito mais fruto do medo de punição, do que consequência de um sentimento de compromisso eadesão a elas. Este tipo de motivação no seguimento de regras e normas tem outra consequência indesejável, que é a desobediência às mesmas quando não há risco de punição antecipado pelo transgressor. Assim, o ideal é que reuniões ou assembleias sejam realizadas regularmente na escola para discussão das normas, e so bretudo, os princípios que as sustentam, como, por exemplo, o respeito eajustiça, ou mesmo sua racionalidade, em termos

Rev. Diálogo Educ., Curitiba, v. 9, n. 28, p. 541-555, set./ dez. 2009 
dos custos decorrentes da indisciplina para a aprendizagem. É muito importante explicitar para os alunos estes princípios, certificar-se do seu entendimento sobre os mesmos e suas consequências, assim como 0 compromisso representado pela sua participação na elaboração e decisão das mesmas. É necessário também considerar sugestões ou opiniões diferentes das próprias, promover diálogo so bre suaviabilidadeepertinência, o que assegura aos seus propositores o real acolhimento da divergência. $\dot{E}$ importante que o diretor e o corpo docente sejam exemplos concretos de atuação democrática, que só ocorre pela consideração da diversidade de posições, condição necessária para a sualegitimação. Namesmaperspectiva, deve ficar claro outro sentido de democracia, em termos do que o voto representa em termos de responsabilidade e adesão, mesmo que diferente do decidido pela maioria. Não se pretende com isso destituir a equipe gestora de autoridade, mas distribuir o poder mais equitativamente na comunidade escolar. É claro que aqueles que respondem pela integridade da instituição, como diretores e outros membros da equipe gestora, devem tergarantidos mais direitos do queaqueles quetêm menosresponsabilidades em relação a ela, como os alunos, por exemplo. Mas, de todo modo, estes últimos devem ser ouvidos e considerados, pois só assim se sentirão acolhidos, respeitados e responsáveis pelas regras também.

É importante ainda que as regras e as consequências advindas da desobediência sejam não só fruto da decisão coletiva como analisado acima, mas ainda que estejam formuladas de modo claro, não permitindo mais de uma interpretação. D evem ainda estar registradas em meios acessíveis a todos. As consequências às transgressões, por sua vez, devem ser proporcionais às faltas cometidas, visando antes de tudo 0 melhor interesse do aluno. Assim, deve-se evitar as punições que implicam em exclusão do aluno do cotidiano escolar, como ocorre quando se aplicam suspensões e transferências de estabelecimento de ensino. Essas punições só devem ser aplicadas quando a permanência do aluno transgressor representa risco à integridade física dos integrantes da comunidade escolar. Isso porque as práticas que afastam o aluno das aulas e outras atividades podem perpetuar o círculo vicioso da violência. As ausências de aulas e provas podem limitar o seu progresso acadêmico, e, portanto, as oportunidades de trabalho no futuro, só restando a transgressão como meio de subsistência. Isto não equivale a dizer que as transgressões devam permanecerimpunes, mas além de proporcionais à falta cometida, devem ser pedagógicas em si, como, por exemplo, reparação de dano ocasionado por depredação, etc.

Rev. Diálogo Educ., Curitiba, v. 9, n. 28, p. 541-555, set./ dez. 2009 
É importante lembrar que a gestão de conflitos entre alunos não se restringe ao diretor. D ocentes e funcionários, pelo contato mais frequente com os alunos, talvez testemunhem muito mais esse tipo de incidente e apliquem muito mais as regras e sanções do que os diretores. Assim, uma providência importante a ser tomada pelos gestores para diminuir a incidência de conflitos na escola é a sensibilização de docentes e funcionários sobre a importância de tratar a todos os alunos do mesmo modo, não privilegiando alguns em detrimento de outros, ou fazendo valer as regras de modo inconsistente, dependendo da ocasião, estado de humor etc. Como verificamos na pesquisa já mencionada anteriormente (LEME, 2006) não só os alunos queixam-se de injustiça na aplicação das regras de disciplina, mas os próprios diretores demonstraram acreditar na procedência da queixa. Ao responderem sobre aspectos como adequação das regras, justiça na aplicação das mesmas pelos professores, cerca de um décimo ou mais dos diretores manifestou dúvidas a este respeito.Apesar disso, informaram delegar aos professores a gestão de algumas transgressões consideradas menos graves, em sua maioria discussões e desentendimentos verbais entre alunos, o que coincide com o encontrado em outras pesquisas (RUOTTI, 2006). Nesse sentido, é importante que os docentes e funcionários sejam formados para aplicar as regras de disciplina de modo consistente, mediar conflitos sem tentar resolvê-los, ou impedi-los para garantir um ambiente pacífico.

Vale lembrar ainda, que os diretores informaram, na mesma pesquisa, que preferem ser avisados nos casos de transgressões mais graves como roubos, agressões físicas etc. Nessas ocasiões, adotam provavelmente a prática, bastante rotineira nas escolas, de chamar a família, usualmente responsabilizada pela transgressão do aluno, tendo em vista que no entender dos gestores, os conflitos ocorrem porque a educação familiar dos educandos é permissiva (LEME, 2006). Esta prática de convocação da família para resolver problemas disciplinares é pouco adequada, em vista da diferença de contextos entre escola e lar, que ocasionam conflitos diferentes. Mas, mais importante que essas diferenças, convocar a família evidencia que a escola não considera seu dever educar o aluno, além do âmbito do conhecimento acadêmico, o que provavelmente contribui para a violência, em vista da ausência de responsabilidade atribuída àinstituição pelos mesmos. Em outras palavras, ao culpar o aluno ou sua família pelos conflitos que ocorrem na escola, os diretores isentam, total ou parcialmente, a instituição de sua parcela de responsabilidade, e

Rev. Diálogo Educ., Curitiba, v. 9, n. 28, p. 541-555, set./ dez. 2009 
também, se eximem de qualquer participação nos mesmos.Assim, não revisam, nem discutem com a comunidade as normas de disciplina no sentido de aperfeiçoá-las, permitem injustiças na aplicação de sanções às transgressões, enfim, não cogitam que o problema possa também estar na escola, e não apenas fora dela.

\section{CONCLUSÕES}

Finalizando esta análise, vale reiterar que a redução da violência na escola e consequente melhoria do seu convívio implicam em vários níveis de atuação, desde a desempenhada pelos órgãos gestores centrais, que elaboram políticas e implementam programas, até a unidade escolar, que precisa estar mobilizada para acolher essas iniciativas, o que envolve necessariamente toda a comunidade. E é justamente nesse nível que 0 diretor tem um papel crucial, na gestão voltada para esta mobilização. Para tanto, é preciso que acredite que a instituição tem sua parcela de responsabilidade pela violência que ocorre em seu interior, e assim valorize ações que possam diminuí-la, ou até mesmo erradicá-la. Estas ações vão desde o zelar pelo cumprimento da missão pedagógica da escola, pela exigência de profissionalismo do corpo docente e garantia de um ambiente favorável à aprendizagem, até a democratização da gestão, abrindo a discussão acerca das decisões sobre o funcionamento e disciplina. Isso implica que as regras de disciplina devem ser fruto de decisão coletiva e aplicadas com justiça e consistência, tanto em sala de aula como fora dela. Para implementar essas medidas são necessárias a sensibilização e formação não só de docentes, mas de todos os envolvidos na aplicação das regras, como, por exemplo, funcionários. A lém disso, deve haver preocupação com o melhor interesse também do aluno que transgride, o que significa consequências associadas à inclusão e não exclusão por suspensões e transferências. Finalmente, devem ser promovidas atividades como conferências, debates para esclarecimento e sensibilização de princípios de convivência para toda a comunidade. A abertura da escola para a comunidade de modo a favorecer a proximidade das famílias, a sociabilidade entre alunos e uma relação mais positiva com a instituição é também uma boa medida a ser adotada como as políticas públicas já mostraram. Essas devem ser articuladas, consistentes, e acompanhadas ao longo da implantação para que venham surtir o efeito pretendido.

Rev. Diálogo Educ., Curitiba, v. 9, n. 28, p. 541-555, set./ dez. 2009 


\section{RE FERÊ NCIAS}

ABRAMOVAY, M. Entrevista ao e.educacional. 2004. Entrevista concedida a Diogo D reyer. Disponível em: <http:/ / www.educacional.com.br/ login/ acessorestrito.asp?restr=0\&URL=/ entrevistas/ entrevista0111.asp > . Acesso em: 2 set. 2006.

ABRAMOVAY, M. et al. Juventude, violência e vulnerabilidade social na América Latina. Brasília: Unesco, 2002.

ALVES, R. As escolas em bairros com altas taxas de violência: a visão dos professores. In: RUOTTI, C.; ALVES, R.; CUBAS, V. O. (O rg.). Violência na escola: um guia para pais e professores. São Paulo: AND HEP/ Imprensa O ficial, 2006. p. 109-147.

CAMACHO, L. M. Y. As sutilezas das faces da violência nas práticas escolares de adolescentes. Educ. Pesqui., São Paulo, v. 27, n. 1, p. 123-140, 2001.

CO RREA, D. M. Avaliação das políticas públicas para a redução da violência escolar em Minas Gerais: o caso do projeto Escola Viva, Comunidade A tiva. 2007. 160 f. D issertação (Mestrado em Educação) - Universidade Federal de Minas Gerais, Belo Horizonte, 2007.

D E SO USA, E. R.; RIBEIRO, J. Bullying and sexual harassment among Brazilian high school students. Journal of Interpersonal Violence, Thousand $O$ aks, v. 9, n. 20, p. 1018-1038, 2005.

DICE, P. et al. The health behavior in school aged children bullying working group. Bullying and symptoms among school aged children: international comparative cross sectional study in 28 countries. European Journal of Public Health, Oxford, v. 15, n. 2, p. 128-132, 2005.

DO MINGOS, B. Escola e violência: configurações da violência escolar segundo alunos, professores, pais e moradores da comunidade. 2005. 356 f. Tese (D outorado em Psicologia) - Instituto de Psicologia, Universidade de São Paulo, São Paulo, 2005.

ESLIA, M. et al. Friendship and loneliness among bullies and victims: data from seven countries. Aggressive Behavior, Hoboken, v. 30, n. 1, p. 71-83, 2004.

FANTE, C. Fenômeno bullying: estratégias de intervenção e prevenção da violência entre escolares. São José do Rio Preto, SP: Ativa, 2003.

GO NÇALVES, L. A.; SPO SITO, M. P. Iniciativas públicas de redução da violência escolar no Brasil. Cad. Pesqui., São Paulo, n. 115, p. 101-138, 2002.

Rev. Diálogo Educ., Curitiba, v. 9, n. 28, p. 541-555, set./ dez. 2009 
LEME, M. I. S. Convivência, conflitos e educação nas escolas de São Paulo. São Paulo: ISME, 2006.

LIBERAL, E. F. et al. Escola segura. Jornal de Pediatria, Rio de Janeiro, n. 81, p. 155-163, 2005.

NAMO DE MELLO, G.; ATHIÉ, L. Gestão escolar eficaz. 2003. D isponível em: <www.rededosaber.sp.gov.br>. Acesso em: 20 fev. 2008.

NEWMAN, M. L.; HOLDEN, G. W.; DELVILLE, Y. Isolation and the stress of being bullied. Journal of Adolescence, Amsterdam, v. 28, n. 3, p. 343-357, 2005.

RUOTTI, C. Prevenção da violência escolar. In: RUOTTI, C.; ALVES, R.; CUBAS, V. O. (Org.). Violência na escola: um guia para pais e professores. São Paulo: Imprensa O ficial, 2006. p. 209-228.

SAVIANI, D. Papel do diretor de escola numa sociedade em crise. In:

Educação: do senso comum à consciência filosófica. Campinas: Autores Associados, 2000. p. 207-210.

SPO SITO, M. Um breve balanço da pesquisa sobre violência escolar no Brasil. Educ. Pesqui., São Paulo, v. 27, n. 1, 87-103, 2001.

TOBLIN, R. L. et al. Social-cognitive and behavioral attributes of aggressive victims of bullying. Journal of Applied Developmental Psychology, Amsterdam, v. 26, n. 3, p. 329-346, 2005.

VIENSTRA, R. et al. Bullying and victimization in elementary schools; a comparison of bullies, victims, bullies/ victims and uninvolved adolescents. Developmental Psychology, Washington, v. 41, n. 4, p. 672-682, 2005.

Recebido: 04/ 03/ 2009

Recived: 03/ 04/ 2009

A provado: 02/ 04/ 2009

Approed 04/ 02/ 2009

Revisado: 17/ 09/ 2009

Reviened: 09/ 17/ 2009

Rev. Diálogo Educ., Curitiba, v. 9, n. 28, p. 541-555, set./ dez. 2009 